\title{
Envisioning alternative futures of socio-ecological practice: navigating an uncertain world with a compass of scenarios
}

\author{
Wei-Ning Xiang ${ }^{1}$
}

Published online: 7 September 2020

(c) Springer Nature Singapore Pte Ltd. 2020

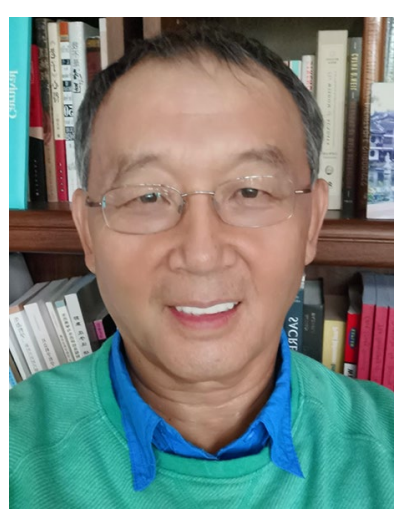

Wei-Ning Xiang, the editor in chief

The editor in chief of Socio-Ecological Practice Research (SEPR) plans to publish a special issue in 2021 with the theme Our alternative futures in the 2020s and beyond: scenarios of socio-ecological practice in an uncertain world. This Call for Prospectus outlines the aims and scope of the special issue and provides guidelines for the prospectus preparation and submission.

\section{What does the SEPR editor look for and why?}

In his widely acclaimed book The art of the long view: planning for the future in an uncertain world, American futurist Peter Schwartz claims, on the grounds of the latest evidence from neuroscience, that we, the human beings, are "the scenario-building animal" who has an innate ability

Wei-Ning Xiang

wxiang@uncc.edu

1 University of North Carolina at Charlotte, Charlotte, NC, USA to compose scenarios and, through such a scenario lens, to foresee possible futures for decision-making in an uncertain world (Schwartz 1996, p. 29).

The ongoing COVID-19 pandemic presents a unique opportunity for us to take full advantage of this scenariobuilding capability in our strategic thinking and planning for coping with this hitherto unprecedented common threat and its unpredictable aftermath. ${ }^{1}$

To grasp this window of opportunity, the SEPR editor looks for contributions from around the world that compose socio-ecological practice scenarios

1. to foresee alternative futures of socio-ecological practice in the 2020s and beyond: What would the socio-ecological practice look like in the aftermath of this pandemic? What if the pandemic persists indefinitely? and

2. to envision, under each alternative future, the correspondingly coping strategies for socio-ecological practitioners and scholars: How could socio-ecological practitioners cope? Could they "reboot" (Collier 2020)? If so, how and at what cost? How could scholars conduct socio-ecological practice research that is usefuldirectly relevant, immediately actionable, and foreseeably efficacious (Xiang 2019a, p.9)?

As an instrument for strategic thinking and option search, a socio-ecological practice scenario by definition is a synopsis of a possible (not probable) sequence of events or course of action in socio-ecological practice an individual or group imagined (for a generic scenario definition, see MerriamWebster 2020a). In taking the long view into alternative

\footnotetext{
1 A common threat by definition is a danger-something or someone that can hurt or harm people - that might happen to every individual human being in a certain place. A common threat comes either from a natural disaster or human conflict to which no one in a certain place (e.g., the earth, a country, a region, a city, a village, a community, etc.) is immune. At the global scale, for example, the COVID-19 pandemic exemplifies the former, and World War II the latter (Palko and Xiang 2020).
} 
futures and imagining prudent courses of action, all socioecological practice scenarios in the special issue articles are expected to be both strategic and practical.

\section{How may scenarists compose socio-ecological practice scenarios for the special issue?}

The editor offers a few tips below for the scenario composers and writers (i.e., scenarists) in their exercise of scenario composition and writing.

\subsection{The focus, vantage point, and spatial scale}

Socio-ecological practice by definition is the human action and social process that take place in specific socio-ecological context to bring about a secure, harmonious, and sustainable socio-ecological condition serving human beings' need for survival, development, and flourishing. It includes six distinct yet intertwining classes of human action and social process-planning, design, construction, restoration, conservation, and management (Xiang 2019a, p. 7).

In composing socio-ecological practice scenarios for their SEPR articles, the scenarists may focus on one or any combination of the six components of socio-ecological practice abovementioned; they may take any vantage points-political, social, ecological, cultural, economic, historical, philosophical; they may choose a socio-ecological context at any spatial scale, ranging from community/neighborhood, city/ town, state/province, to country/continent, and the world.

\subsection{The time frame}

"Scenarists often advise publicly that the (scenario) users should not take the time frames within which the scenarios are formulated too precisely nor too seriously. They certainly do not themselves" (Xiang and Clarke 2003, p. 900; parenthesis by the author). For a recent example, in their 2018 best seller How democracies die, American political scientists Steven Levitsky and Daniel Ziblatt compose three scenarios to envision "three possible futures for a post-Trump America" with an unspecified time frame (Levitsky and Ziblatt 2018, pp. 206-213).

In the same spirit, the time frame "the 2020s and beyond" in the special issue theme serves as a general reference of future and should not be taken too strictly by our scenarists.

\subsection{References to start with}

In their 2003 article The use of scenarios in land-use planning, Chinese-American geographer and planning scholar Wei-Ning Xiang and British-American cartographer Keith
Clarke review the concepts, methods, and applications of scenarios in a specific field of socio-ecological practiceland-use planning (Xiang and Clarke 2003). For the prospective scenarists who are less familiar with the scenario literature, that article and Schwartz's 1996 book together with a recent article by American planning scholars Uri Avin and Robert Goodspeed (Avin \& Goodspeed (2020), and Robert Goodspeed's new book (Goodspeed 2020) can help jumpstart their adventure.

\subsection{Good scenarios}

According to Xiang and Clarke (2003), scenarios function both as a bridge that connects the process of analysis/modeling with that of planning, and as a cognitive apparatus that stretches people's thinking and broadens their views in planning (Ibid., p. 888); furthermore, to be effective, good scenarios should possess an ensemble of three essential credentials: plausible unexpectedness, informational vividness, and cognitively ergonomic design (Ibid., pp. 890-901).

The scenarists are encouraged to refer to these and other credentials in more recent literature [e.g., in Goodspeed (2020)] in their endeavor to compose and write good scenarios.

\subsection{Perspicuous presentation}

Perspicuity is the quality of being plain to the understanding because of clarity, elegance, precision, and simplicity of presentation (Merriam-Webster 2020b). For many scholars, represented by (but certainly not limited to) Scottish philosopher and political economist Adam Smith (1723-1790), perspicuity is the gold standard for all their works (Xiang 2020, p. 125). Our scenarists are encouraged to pursue perspicuity in presenting their scenarios.

\subsection{Article types}

The journal Socio-Ecological Practice Research (SEPR) has a fleet of 11 article types that fall into five clusters [See Table 1 in Xiang (2019b)]. Our scenarists may choose the one that best fits their need.

\section{Prospectus preparation and submission}

Prospective authors should send a brief prospectus (250-350 words) in a word document before or on October 15,2020 to the SEPR editor in chief Wei-Ning Xiang at wxiang@uncc.edu. The prospectus should outline

1. What the article is about-the aim(s), thesis, and scenarios to be composed; 
2. Who the scenario users would be-the people who would benefit from and potentially use the scenarios in their socio-ecological practice and research;

3. How the article contributes to the aims and scope of the special issue (as presented in Sects. 1 and 2 above);

4. Whether a manuscript can be submitted by January 22 , 2021 should the prospectus be accepted.

The prospectuses will be selected on a rolling basis against the following criteria:

1. relevance to the theme of the special issue;

2. compliance with the scenario requirements outlined in Sect. 2;

3. writing ABC (accuracy, brevity, clarity);

4. single authorship is preferred, but multiple authorship considered;

5. commitment to meeting the manuscript submission deadline.

All questions should be directed to Wei-Ning Xiang at wxiang@uncc.edu; information about the journal SEPR and the articles SEPR published can be found at https://www.sprin ger.com/journal/42532.

\section{References}

Avin U, Goodspeed R (2020) Using exploratory scenarios in planning practice: a spectrum of approaches. J Am Plan Assoc. https://doi. org/10.1080/01944363.2020.1746688
Collier C (2020) Post pandemic: will cities choose to reboot? Smart Cities Connect. https://smartcitiesconnect.org/post-pandemicwill-cities-choose-to-reboot/. Accessed 26 Aug 2020

Goodspeed R (2020) Scenario planning for cities and regions managing and envisioning uncertain futures. Lincoln Institute of Land Policy, Cambridge

Levitsky S, Ziblatt D (2018) How democracies die. Broadway Books, New York

Merriam-Webster (2020a) Scenario. In: Merriam-Webster.com dictionary. Retrieved August 15, 2020, from https://www.merriam-webst er.com/dictionary/scenario

Merriam-Webster (2020b) Perspicuity. In: Merriam-Webster.com dictionary. Retrieved August 15, 2020, from https://www.merriamwebster.com/dictionary/scenario

Palko HC, Xiang W-N (2020) In fighting common threats, people's deep commitment to taking collective action matters: examples from China's COVID-19 battle and her other combats. Socio-Ecol Pract Res. https://doi.org/10.1007/s42532-020-00056-1

Schwartz P (1996) The art of the long view: planning for the future in an uncertain world. Doubleday, New York

Xiang W-N (2019a) Ecopracticology: the study of socio-ecological practice. Socio-Ecol Pract Res 1(1):7-14. https://doi.org/10.1007/ s42532-019-00006-6

Xiang W-N (2019b) Socio-Ecological Practice Research (SEPR): What does the journal have to offer? Socio-Ecological Practice Research $1(1): 1-5$

Xiang W-N (2020) From good practice for good practice we theorize; in small words for big circles we write. Socio-Ecol Pract Res 2(1):121-128. https://doi.org/10.1007/s42532-020-00040-9

Xiang W-N, Clarke KC (2003) The use of scenarios in land-use planning. Environ Plan 30(6):885-909 